\title{
Um Estudo Inferencial dos Custos Ambientais e das Estações de Tratamento de Água nas Lavanderias do Polo de Confecções do Agreste de Pernambuco
}

An Inferential Study of Environmental Costs and of Water Treatment Stations in Laundry of Polo Clothes of Agreste Pernambucano

\section{Lavoisiene Rodrigues de Lima}

Mestre pelo Programa de Pós-Graduação de Ciências Contábeis pela UFPE.

Professora em tempo integral no Curso de Ciências Contábeis do Centro Universitário do Vale do Ipojuca - UNIFAVIP/Devry.

Ave. Abel Ambrosio da Silva, 16. Boa Vista I. Caruaru-PE

CEP: $55038-170$

E-mail: lavoisiene@ hotmail.com

Telefone: (81) 3721-1216/ 99182-5073/ 99748-2410.

\section{Yony de Sá Barreto Sampaio}

Ph.D. Program Economias Agrária e Recursos Naturais na Universidade de Grenoble

Professor Titular do Departamento de Ciências Sociais Aplicadas da UFPE

Ave. dos Economistas, s/n. Cidade Universitária. Recife - PE.

CEP: 50670-901

E-mail: yonysampaio@gmail.com

Telefone: (81) 2126-8911

\section{Maurício Assuero Lima de Freitas}

Doutor em Economia pela Universidade Federal de Pernambuco

Prof. Adjunto do Departamento de Ciências Contábeis e Atuariais e Assessor do Reitor Ave. dos Economistas, s/n. Cidade Universitária. Recife - PE.

CEP: 50670-90

E-mail: massuero@ig.com.br

Telefone: (81) 2126-8911/99197-4899

\section{Umbelina Cravo Teixeira Lagioia}

Doutora em Administração pela Universidade Federal de Pernambuco - UFPE

Professora Adjunta do Departamento de Ciências de Ciências Contábeis da UFPE

Ave. dos Economistas, s/n. Cidade Universitária. Recife - PE.

CEP: 50670-901

E-mail: umbelinalagioia@gmail.com

Telefone: (81) 2126-8911/98854-0770. 


\title{
Resumo
}

Este artigo verifica se há impacto nos custos operacionais com a implantação de medidas sustentáveis como a instalação uma estação de tratamento de água nas lavanderias têxteis do Polo de Confecções do Agreste Pernambucano. Amostra contou com 45 (quarenta e cinco) lavanderias têxteis de jeans. As hipóteses levantadas consistem em avaliar há influência dos custos ambientais internos ou externos diante a gestão operacional da empresa; e a segunda premissa foi verificar se a Estação de tratamento de água influência nos custos das lavanderias investigadas. Então após utilização do software SPSS versão 20, pode-se verificar através do método Fischer que aceita-se em parte ambas hipóteses, pois as variáveis dos custos ambientais internos e externos demostraram significância com as variáveis independentes, assim pode-se concluir que a sustentabilidade pode vim a reduzir os custos e evitar sanções além de beneficiar toda sociedade.

Palavras chaves: Estação de tratamento de água; Lavandeira Têxtil de Jeans; Polo de Confecções do Agreste Pernambucano.

\begin{abstract}
Abstrat
This article checks for impact on operating costs by implementing sustainable measures such as installing a water treatment plant in the textile laundries Polo Clothes do Agreste Pernambucano. Sample consisted of 45 (forty five) textile laundries jeans. The hypotheses are to assess no influence of internal or external environmental costs on the operational management of the company; and the second premise was to determine whether the water treatment plant influence on the investigated laundries costs. So after using SPSS software version 20 , can be seen through the Fischer method which is accepted in part both assumptions for the variables of internal and external environmental costs demonstrated significance with the independent variables, so it can be concluded that sustainability can I came to cut costs and avoid penalties in addition to benefit the whole society.
\end{abstract}

Key words: Water treatment plant; Laundry Textile Jeans; Polo Clothes do Agreste Pernambucano.

\section{Introdução}

Segundo a Associação Nacional das Empresas de Lavandeira (ANEL), no Brasil existem mais de 9 mil lavanderias e destas, 1,5 mil atendem a indústrias, hotéis e hospitais. A associação prevê que existirá um aumento de $6 \%$ a $8 \%$ neste setor até 2016 , no Produto Interno Bruto-PIB, como reflexo dos eventos desportivos no País. (SEBRAE, 2012)

Dados do Ministério do Desenvolvimento, Indústria e Comércio Exterior (BRASIL/ MDIC, 2012), indicam que o Estado de Pernambuco está em contínua expansão econômica, e diversos setores são responsáveis por esse impulso na economia, em torno de 4,6\% em 2011 no PIB. Um dos setores que merece destaque é o setor têxtil, com mais de 20 mil empresas, gerando 150 mil empregos diretos e indiretos. E como reflexo deste setor, as lavanderias têxteis empregam 1,7 milhão de pessoas em todo o país. 
As lavanderias têxteis são indústrias que necessitam de muita água para seu processo principal, portanto, estão propícias a afetar o meio ambiente. É o que Brito (2013, p. 11) destaca em sua pesquisa realizada com lavanderias têxteis quando expõe que:

\footnotetext{
"Os processos que consomem mais recursos naturais, que geram maior poluição e que são insalubres e perigosos tendem a localizar-se em países e/ou regiões que apresentam legislações ambientais e trabalhistas menos rigorosas.".
}

Se uma determinada atividade requer muitos recursos ambientais, como no caso das lavanderias têxteis de jeans, e seus resíduos de fabricação podem afetar o meio ambiente, então podem causar danos ambientais. Os danos ambientais são, segundo Braga (2010, p. 27), "uma alteração indesejável ao conjunto de elementos chamados meio ambiente, que será considerado no seu aspecto amplo".

Devidos a esses danos, as lavanderias têm sido alvo de discussão no Governo Estadual de Pernambuco, que realiza fiscalizações e é auxiliado pelo Mistério Público do Estado (MPPE), o qual implanta medidas corretivas sobre as lavanderias. As medidas vão desde a distribuição de um Selo Verde, para mitigar os impactos ambientais, em parceria com o Serviço Brasileiro de Apoio às Micro e Pequenas Empresas (SEBRAE, 2013). O MPPE pode até vetar a instalação de novas lavanderias nas cidades pertencentes ao Polo, caso as demais, já instaladas ainda não estejam devidamente regulamentadas.

Outra ação do MPPE foi exigir que os proprietários das lavanderias assinassem diversos Termos de Ajustamento de Conduta (TAC), comprometendo-se a adotar as medidas necessárias para fazer cessar a poluição sonora, ambiental e instalar até julho de 2015 estações de tratamento de água (ETA). Conforme divulgado no Diário Oficial n 187 de Outubro de 2012. Mas, apesar dessas medidas, muitas lavanderias ainda continuam sem utilizar o sistema de tratamento de água, ou não utilizam corretamente, por medo de elevaram seus custos.

Portanto, esta pesquisa traz o seguinte questionamento: Será que há impacto nos custos operacionais com a implantação de medidas sustentáveis como a instalação uma estação de tratamento de água nas lavanderias? Pois se as mesmas já serão incumbidas de cumprir com o que determina a lei podem ficar propícia às multas e sanções.

Assim o objetivo deste artigo foi averiguar se há impacto nos custos ambientais com a implantação de medidas sustentáveis como a instalação uma estação de tratamento de água nas lavanderias, observando se há influência dos custos ambientes internos ou externos diante da gestão operacional da empresa (diga-se, hipótese 1) e se a estação de tratamento de água influência nos custos das lavanderias investigadas (diga-se, hipótese 2).

A literatura e pesquisas anteriores indicam que ao implantar atividades de gestão ambiental, as lavanderias estariam investindo nos ativos ambientais, em prol da redução dos passivos ambientais, principalmente dos referentes aos custos externos, e por consequência devem repassar esses custos aos produtos, neste caso, na sua prestação de serviços, enfatizando que o retorno será mais benéfico à sociedade. Assim esta pesquisa visa comprovar tais premissas. 


\section{Revisão da literatura}

\subsection{Lavanderias}

As lavanderias de jeans são consideradas como indústrias, pois transformam a peça, dando diversos acabamentos que passam por algumas etapas como cita Marx (2013): Beneficiamento; Stone Wash; Délavé; Dirty Washed; Acid Washed; Destroyed; Resinado e Bigode. Os procedimentos partem da recepção e triagem da peça que recebem o acabamento conforme se deseja, ao final do processo é gerado o lodo e a água segue para tratamento dos efluentes, podendo ser descartada ou reutilizada.

Durante esses processos há diversos produtos químicos, que podem vir a causar danos à saúde humana ou ambiental, caso não sejam devidamente manuseados. Costa (2008) aponta quais os produtos utilizados nos processos de lavagem do jeans: corantes reativos, básicos, ácidos, mordentes, diretos ou substantivos, azoicos, de enxofre, pré-metalizado, branqueadores, a cuba ou tina.

Além desses produtos, destacam-se dois produtos prejudiciais à saúde humana: o percloroetileno e o permanganato de potássio. O percloroetileno é um gás solvente que serve como removedor de tinta e que ocasiona diversos sintomas ao ser humano, em alguns casos quando o resíduo é inalado, podem causar enjoos, fadiga, dores de cabeça e a perda da consciência ou até mesmo câncer (VIÑOLAS, 2005).

A Agência de Vigilância Sanitária (ANVISA), através da Resolução da Diretoria Colegiada (RDC) 161, de 23/06/2004, estabelece regras para a utilização do percloroetileno, no objetivo de proteger o meio ambiente e a saúde da população e dos trabalhadores.

Já o Permanganato de potássio é um composto químico que serve como agente oxidante, de coloração violeta. Nas lavanderias de jeans é usado para desbotar a peça, conforme indica o Sindicato de lavanderias de São Paulo-SP (SINDILAV, 2011).

O permanganato de potássio também contém em sua composição o metal manganês que pode causar psicose, perda da expressão facial, ausência do ato de piscar, gagueira e insônia, tremores nas mãos, rigidez dos membros e outros sintomas similares à doença de Parkinson (TEIXEIRA, 2010).

Medidas corretivas foram discutidas no Congresso da Associação Brasileira de Técnicos Têxteis em 2011, onde grandes marcas de jeans apresentaram suas tecnologias sustentáveis, como a utilização da marcação no jeans por laser que substituir o jato de areia, a utilização do permanganato de potássio e o esmeril; outra técnica é o uso do ozônio, que reduz o uso da água e a utilização de produtos químicos (SINDILAV, 2011).

Silva filho (2013) aponta outros possíveis impactos derivados do processo geral das atividades de uma lavanderia têxtil de jeans, Pode-se avaliar que existem cinco tipos de impactos relacionados às lavanderias, destes, três são causados pela não utilização da estação de tratamento de água, como o desperdício de água, a contaminação nas águas e contaminação atmosférica e geração de lixo sólido (fibras de tecido, cinza e resto de pedras).

Por isso as lavanderias devem cumprir com diversas leis ambientais, como por exemplo, a Lei ambiental $n^{\circ} 9.605 / 98$, que dispõe das sanções penais e administrativas derivadas de condutas e atividades lesivas ao meio ambiente. Por ser uma atividade que envolve muitos recursos ambientais como água e lenha, esta Lei impõe, no $\S 2^{\circ}$ do Art. 25, que caso a empresa 
seja pega comprando ou armazenando a lenha indevidamente, estes itens serão avaliados e doados a instituições científicas, hospitalares, penais e outras com fins beneficentes.

E aquelas que não tratarem seus efluentes antes do despejo ou reuso podem sofrer multa ou detenção de um a três anos, principalmente se essa emissão de efluentes ocasionar "o perecimento de espécimes da fauna aquática existentes em rios, lagos, açudes, lagoas, baías ou águas jurisdicionais brasileiras" (Art. 33 da mesma lei).

A Lei 9.605/98 também trata em seu Art. 54 que todo aquele que causar poluição atmosférica ou causar poluição hídrica, incorrerá na pena com reclusão de um a cinco anos. Sendo assim, as lavanderias têxteis de jeans, estão propícias a produzirem resíduos atmosféricos com a queima de lenha na caldeira; a sua atividade gera efluentes líquidos que caso não sejam tratados ou despejados em rede pluvial e que desaguem para mananciais de abastecimento de água podem gerar poluição que comprometa o abastecimento.

Já perante o Estado de Pernambuco, as lavanderias devem cumprir com a Lei 14.249/10 e suas alterações, estando sujeitas a receber sanções administrativas caso não cumpram com o estabelecido. O Art. 40 desta Lei considera infração administrativa ambiental toda ação ou omissão que resulte em poluição ou degradação ambiental. A lei 14.249/10 ainda impõe os valores de multas conforme o dano ambiental no Art. 42, que determina que o infrator deva reparar o dano ambiental por ele causado e ficará sujeito a sanções civis e penais ou a multas vão de $\mathrm{R} \$ 50,00$ a 50 milhões de reais.

Em 2005, 20 lavanderias de Toritama-PE foram interditadas até que cumprissem com um Termo de Ajustamento de Conduta-TAC firmado entre elas e o MPPE. Mais tarde, em 2012, após denúncias da população, as lavanderias da cidade de Caruaru-PE, também foram convidadas a assinarem o TAC, para o cumprimento de autos de inquéritos civis no objetivo que as lavanderias cumpram com ajustamento da conduta ambiental das mesmas, para isso foram levados em consideração vários pontos. Tais como: a localização das lavanderias em bairros residenciais; a utilização das caldeiras sem a inspeção regulamentar; a queima de lenha emitindo poluição atmosférica; as denúncias da população quanto à poluição sonora e a dificuldade de monitoramento de efluentes líquidos.

O termo também pretendeu apresentar vantagens aos empresários do ramo de lavanderias têxtis, como a doação de uma área do distrito industrial cedida pela Prefeitura do Município, destinada para transferência das lavanderias que não possuem porte para instalação de estações de tratamento de água, de forma individual. Sendo necessário que o responsável legal apresentasse o projeto de instalação à Secretaria de Desenvolvimento Econômico da cidade, para que a mesma destinasse a verba e terreno necessário.

Diante do termo, pode-se verificar que, caso o TAC (2012) não seja cumprido no período estabelecido de 3 anos, ou seja, em julho de 2015, e as lavanderias não sejam transferidas para o Distrito Industrial e/ou implantado o sistema de tratamento de água individual ou comunitária, serão aplicadas as sanções predeterminadas e terão o estabelecimento interditado. Para que isso não aconteça, várias lavanderias vêm tomando uma atitude sustentável para manter seu negócio e cumpri com o que determina a justiça para com o meio ambiente.

\subsection{Estação de tratamento de água - ETA}


Por ser uma atividade que requer de muita água, e por existe uma escassez de recursos hídricos na Região Agreste de Pernambuco, isso acentua o maior incentivo à prática de reuso nas lavanderias têxteis (RESENDE, 2012). O que é reforçado por Fijan, Fijan, Sostar-Turk (2007) que relatam que água é usada em grandes quantidades em lavanderias e atualmente elas estão emitindo relativamente altas quantidades de águas residuais.

Chen; Ngo e Guo (2012) afirmam que a água reciclada é uma oportunidade viável para complementar o abastecimento de água, bem como aliviar cargas ambientais. Com base nesta afirmação, os autores realizaram um estudo que revisa diversas ferramentas de avaliação ambiental e constataram que como meio de alcançar a sustentabilidade é necessário um sistema de reciclagem que considere as condições individuais em termos espaciais de cada empresa.

Pensando na economia dos custos e na falta de água na região, o Sr. Edmilson Tavares foi pioneiro na região de Toritama-PE quando instalou a primeira estação de tratamento em 1989, que com o apoio do Instituto de Formação de Profissionais de Entidades Empresariais da Baviera (BFZ) da Alemanha conseguiu construir uma ETA com R \$ 40.000,00, valor dez vezes menor que se fosse comprar (FONSECA, 2013).

E para reutilizar água existem dois métodos, conforme Rebouças, Braga e Tundisi (2006 p. 376/382):

\footnotetext{
Métodos de tratamento físicos:

Adsorção; Centrifugação; Coagulação, floculação, decantação e flotação; Filtração; Separação por membranas; Microfiltração; Ultrafiltração; Osmose reversa; Eletrodiálise; Separação térmica e Stripping (ou extração).

Métodos de tratamento físico-químicos:

Neutralização; Oxidação e redução química; Precipitação química; Troca iônica; Métodos de tratamento biológicos; Digestão aeróbia; Filtros Biológicos; Lagoas aeradas; Digestão anaeróbia;
}

Depois de implantada, o funcionamento da estação de tratamento inicia-se por um misturador hidráulico para receber uma dosagem de produtos químicos sulfato de alumínio ou cloreto férrico, para alcançar a floculação, processo de suspenção da sujeira em flocos na água (REBOUÇAS; BRAGA; TUNDISI, 2006).

É importante ressaltar que a instalação de uma estação de tratamento para reuso de água pode indicar uma economia de até $90 \%$, além do que a indústria estará cumprindo com as leis ambientais e contribuindo para o meio ambiente.

Essas máquinas geralmente são importadas, principalmente da Alemanha, Holanda, Bélgica, Itália e Espanha, hoje em dia existem vários modelos, compactos ou não. No entanto, algumas lavanderias da região ainda podem optar por fazer a ETA com tanques de alvenaria e caixas d'água, seguindo o modelo apresentado pelo Instituto de Formação de Profissionais de Entidades Empresariais da Baviera (BFZ), com a parceira do Sindicato das Indústrias do Vestuário do Estado de PE (SINDIVEST) e juntamente com o Instituto Pernambucano de Tecnologia (ITEP). Assim cada estação é realizada seguindo um padrão mais adequado à capacidade produtiva da lavanderia.

\subsection{Custos Ambientais}


São classificados como custos ambientais, segundo Ribeiro (2006), os consumos de recursos diretamente associados com a utilização do meio ambiente e sobre os efeitos da operação da empresa no meio ambiente.

A matéria-prima e os insumos utilizados diretamente no processo produtivo, que contribuam para a elaboração de bens de menor impacto ambiental, deverão ser considerados como custos ambientais. Bem como, a depreciação de máquinas e equipamentos originados dos ativos ambientais ou serviços próprios ou de terceiros e encargos sociais de pessoal envolvido diretamente com a qualidade ambiental.

Azevedo, Gianluppi e Malafaia (2007) afirmam que a contabilização dos custos ambientais serve de base de integração do setor produtivo com o meio ambiente, devendo ser mensuráveis para auxiliar na elaboração de um preço mais competitivo. Para calcular os custos ambientais das empresas, Tinoco e Kraemer (2011) indicam que se devem somar os custos dos materiais desperdiçados, despesas de manutenção e de depreciação e do trabalho com os custos de salvaguarda ambiental.

Pode-se ver que em todas as atividades existem custos envolvidos no processo de desempenho na empresa, e na contabilidade ambiental os custos são relacionados às atividades não só do processo produtivo, mas de toda a gestão. Para Tinoco e Kraemer (2011, p. 145) "os custos ambientais são apenas um universo mais vasto de custos necessários a uma adequada tomada de decisões". A empresa que aderir a uma gestão ambiental deve manter o controle sobre os custos empregados a questões ambientais.

Braga (2010) afirma que os custos ambientais podem ser identificados com a operação ambiental nas atividades de venda de produtos recicláveis, provindo de tecnologias limpas e relacionados à prevenção, monitoramento, recuperação e reciclagem de resíduos. Estas atividades estão em sua maioria classificadas como custos ambientais externos e internos, os internos por sua vez englobam os diretos e indiretos, os contingentes e os intangíveis. (IFAC, 1998).

Assim, os custos ambientais externos podem incorrer das atividades das empresas sobre o meio ambiente, são difíceis de mensurar em termos monetários, pois estão geralmente fora dos limites das empresas e geralmente muitas empresas não querem internalizar estas externalidades negativas, provindas de danos ambientais. Já os custos ambientais internos são os relacionados aos custos de tratamento e prevenção ambiental.

\subsection{Estudos Anteriores}

Esta pesquisa voltou-se também a relatar pesquisas que tratavam de lavanderias têxteis. Pacher; Vaz e Oliveira (2011, p. 130), em pesquisa realizada com lavanderias em Ponta Grossa, descobriram que muitas lavanderias ainda não apresentam nenhum sistema de tratamento e as que tinham, estavam incompletos. Os autores ainda enfatizam que: "Através de métodos simples elas conseguiriam minimizar os riscos oferecidos pelos produtos utilizados".

Mas, muitas vezes as empresas respeitam o meio ambiente, como foi o caso da lavanderia industrial de Cianorte - PR, na qual, Porto e Schoenhal (2013) verificaram que o processo de tratamento de efluentes e de reuso da água estava de acordo com a Legislação vigente. 
Outro caso de sustentabilidade empresarial em lavanderias foi apresentado por Melo Filho (2012, p. 46) que verificou que: "O processo de reutilização dos recursos hídricos implantado na lavanderia industrial têxtil em estudo possibilitou redução significativa de custos, no que tange à compra de carros-pipa para sua operacionalização diária”.

Em outros países o reuso de água já é uma estratégia utilizada. Thoren, Atwater e Berube (2012) apresentaram um modelo que é usado para reciclar agua urbana no Canadá, no qual esse reuso de água chegaria de 969 a $2000 \mathrm{~m}^{3} /$ ano.

$\mathrm{Na}$ Itália, Ciabattia et al (2009) testaram um tipo de sistema de tratamento de águas para reuso que tem as seguintes etapas: pré-tratamento (coagulação, floculação e flotação), filtração de areia, ozonização, ativo de carbono e uma ultrafiltração em membranas fluoreto. Ao final do tratamento verificou-se que os produtos químicos na água atendem aos limites de lei que exige para descarga de águas superficiais na Itália, o que permitiu a reutilização dos efluentes tratados em alguns processos de lavagem de têxteis. Também foi realizada uma análise de custo para avaliar os custos operacionais de cada etapa do tratamento que resultaram nos seguintes valores: pré-tratamento: 0,42 euros/m3; de areia filtração: 0,04 euros $/ \mathrm{m} 3$; ozonização: 0,10 euros $/ \mathrm{m} 3$; filtração com carbono: 0,09 euros/m3; e Ultrafiltração: 0,16 euros/m3. Assim, os custos operacionais totais da abordagem proposta foram de 0,81 euros $/ \mathrm{m} 3$, uma redução nos custos anteriores.

Outras pesquisas afirmam que a atitude de implantar a estação de tratamento, não basta para equilibrar o tripé da sustentabilidade, é necessário atender a outros fatores, como educação e conscientização ambiental.

\section{Metodologia}

O método de pesquisa foi indutivo, trata-se de um trabalho, que partiu de dados particulares, para alcançar uma demonstração da verdade. O estudo foi realizado através de uma pesquisa de campo in loco, onde foram visitadas as lavanderias das cidades Riacho das Almas, Santa Cruz do Capibaribe, Toritama e Caruaru, pertencentes ao polo de confecções do Estado de Pernambuco.

Classifica-se como pesquisa quantitativa, pois utilizou-se da análise estatística inferencial para que se respondem as hipóteses levantadas tratando os dados inferenciais com o auxilio da versão 20.0 do software Statistical Package for the Social Sciences - SPSS. Partindo do universo de 145 lavanderias cadastradas no Sindicato dos Trabalhadores das Indústrias de Fiação e Tecelagem de Caruaru - SINDITEXTIL, a amostra foi obtida pelo método não probabilístico intencional através do método bola de neve ou snowball, onde parte dos participantes iniciais que indicam novos participantes, que por sua vez indicam novos participantes e assim sucessivamente, totalizando uma amostra de 45 lavanderias respondentes.

Os dados foram coletados através de questionário e para a análise inferencial dos dados efetuou-se a análise da tabulação cruzada, buscando-se, então, a inter-relação dos custos ambientais com os custos operacionais das lavanderias do polo de confecções do Agreste, na intenção verificar se há impacto nos custos operacionais com a implantação de medidas sustentáveis como a instalação uma estação de tratamento de efluentes nas lavanderias.

Os dados foram analisados pelos métodos não paramétricos de correlação o Exato Fischer e Qui-quadrado - $X^{2}$, pois Fonseca e Martins (2011), afirmam que estes métodos não 
exigem suposições referentes à distribuição da população a qual a amostra foi retirada, adequando-se ao tipo de amostra desta pesquisa.

Entretanto, para análise inferencial das variáveis propostas foi considerado apenas o teste Exato de Fisher, recomendado para amostras pequenas, tendo aplicabilidade em determinar se existem associações não aleatórias entre duas variáveis. (SIEGEL, 1975).

Quanto ao nível de significância adotou-se o nível de 5\% para os cruzamentos realizados diante ao Exato de Fisher. Na pesquisa foram evidenciados nos Quadros 01, 02 e 03, desta pesquisa, constando apenas as variáveis que tiveram correlação inferior ou igual a 5\%, as quais foram interpretadas conforme a frequência atingida nos cruzamentos, que apontaram as relações mais afetadas ou não.

\section{Analise dos resultados}

A análise inferencial testada nesta pesquisa utilizou o teste não paramétrico de Exato de Fischer, na qual se obteve 191 correlações, destes 40 cruzamentos foram relacionados aos questionamentos quanto à área ambiental das empresas em estudo.

Entretanto, para responder a hipótese 1, apenas as relações entre os custos ambientais com os custos operacionais foram selecionadas. As 10 correlações foram elencadas em ordem de apresentação no questionário e sendo 08 com os custos ambientais internos e 2 com os custos ambientais externos. Dos custos ambientais apenas o custo com a manutenção dos equipamentos ambientais não teve nenhuma relação com as demais variáveis do estudo.

O quadro 01 apresenta as relações inferenciais quanto aos custos ambientais internos, todas as oito aqui destacadas, apresentaram associação significativa aceitável ( $\mathrm{p}$-valor $\leq 0,05)$ com os custos operacionais, considerando em todos os casos, o teste Exato de Fischer, pois foi o mais indicado quando duas amostras independentes são pequenas.

Quadro 1 - Variáveis dos custos ambientais internos avaliados

\begin{tabular}{|l|c|}
\hline \multicolumn{1}{|c|}{ Custos ambientais internos } & Nível de Significância \\
\hline $\begin{array}{l}\text { Gasto com mão de obra voltada a área ambiental } \\
\text { Gasto com produtos para tratamento ambiental }\end{array}$ & 0,005 \\
\hline $\begin{array}{l}\text { Gasto com produtos para tratamento ambiental } \\
\text { Gasto com energia elétrica mensal }\end{array}$ & 0,013 \\
Gasto com mão de obra voltada a área ambiental & 0,005 \\
\hline Gasto para destinar o lodo gerado pela atividade & 0,034 \\
Gasto com manutenção dos demais equipamentos & \\
\hline Gasto com analise de água & 0,046 \\
Gasto com aluguel mensal & 0,022 \\
Gasto com depreciação nas demais máquinas & 0,009 \\
Gasto com manutenção dos demais equipamentos & 0,023 \\
Gasto com mão de obra voltada a área ambiental & \\
\hline
\end{tabular}

Fonte: Dados da pesquisa, 2013

No primeiro cruzamento a única variável que esteve relacionada com o custo com a mão de obra ambiental como variável dependente foi o custo dos produtos para tratamento da água com $0,5 \%$ de significância, a relação demonstrou que $61,9 \%$ das lavanderias que gastam até $\mathrm{R} \$$ 500,00 com produtos pagam até um salário mínimo ao funcionário que trabalha no local, assim como, $75 \%$ das que compram produtos para tratamento de $\mathrm{R} \$ 1.000,01$ a $\mathrm{R} \$ 1.500,00$. 
Apresentando uma correlação entre quem gasta menos com produtos paga menos aos funcionários, assim como quem gasta mais com tratamento com água, paga mais ao funcionário tratador.

Quando o custo com produtos é relacionado com o gasto com energia elétrica, 75\% dos que não sabem quanto gastam com energia, arcam com tratamento de agua até $\mathrm{R} \$ 500,00 \mathrm{e}$ $50 \%$ dos que gastam acima de $\mathrm{R} \$ 9.000,00$ com energia tem um custo com tratamento ambiental de $\mathrm{R} \$ 1.000,01$ a $\mathrm{R} \$ 1.500,00$, tendo $1,3 \%$ de significância na pesquisa. Implicando que as empresas que gastam mais com energia elétrica também tem um custo alto com produtos.

A relação entre o custo com produtos e custo com mão de obra ambiental indica $0,5 \%$ de grau de significância, apontando que $40 \%$ das lavanderias que gastam acima de R $\$ 2.500,00$ com produtos, pagam aos funcionários acima de $\mathrm{R} \$ 1.500,00$ ao funcionário que fica responsável pelo setor de tratamento, como já foi discutido anteriormente.

A terceira variável analisada foi o custo com a destinação do lodo, que relacionado com o custo de manutenção dos equipamentos, teve um nível de significância de 3,4\%, no cruzamento pode-se identificar que $88 \%$ das lavanderias não gastam com manutenção dos equipamentos, tem um custo de até $\mathrm{R} \$ 250,00$ para destinar o lodo, já 100\% dos que gastam de $\mathrm{R} \$ 1.000,01$ a $\mathrm{R} \$ 5.000,00$ com a manutenção com equipamentos tem um custo de $\mathrm{R} \$ 750,01$ a R \$ 1.000,00 para encaminhar o lodo para o devido local. Demonstrando que independe do valor do aluguel ou do imóvel próprio, a análise da água indefere para ambas as situações.

O quarto custo ambiental interno foi o custo com análise de água que teve um nível de significância de 4,6\% quando relacionado com o pagamento do aluguel mensal, onde $100 \%$ de ambas as faixas de empresas que pagam de $\mathrm{R} \$ 1.000,01$ até 40.000,00 de aluguel, gastam de $\mathrm{R} \$ 350,01$ a $\mathrm{R} \$ 450,0$ para analisar a água e 56,4\% das que não pagam aluguel também pagam o mesmo valor acima para analisar.

Ao cruzar o gasto com análise de água com o gasto com depreciação do maquinário, obteve-se 2,2\% de nível de significância, e comprovou-se que $100 \%$ das lavanderias que informaram que tem um gasto com depreciação mensal até $\mathrm{R} \$ 1.000,00$ gastam acima de $\mathrm{R} \$$ 600,00 para analisar a água, apontando que a depreciação influencia para o gasto com análise de água.

Ainda relacionando o gasto com análise de água agora com o valor pago com manutenção aos equipamentos, verificou-se uma significância de $0,9 \%$ e constatou-se que $100 \%$ das indústrias que gastam de $\mathrm{R} \$ 1.000,01$ a $\mathrm{R} \$ 5.000,00$ com a manutenção, tem um custo acima de $R \$ 600,00$ para analisar a água e as que gastam até $R \$ 1.000,00$ para fazer a manutenção dos equipamentos tem um custo de até $\mathrm{R} \$ 350,00$ para analisar a água da empresa. Assim, quanto maior o gasto com manutenção maior o gasto com análise de água.

Já na relação entre o gasto com análise de agua e a mão de obra especifica para o tratamento ambiental, 55\% das indústrias que pagam mão de obra até um salario mínimo de $\mathrm{R} \$$ 678,00 também pagam de $\mathrm{R} \$ 350,01$ a $\mathrm{R} \$$ 450,00 com análise da agua, tendo um nível de significância de 2,3\%. Está relação pode ser considerada estável, ou seja, os valores relacionados.

Foram analisados também os custos ambientais externos das lavanderias, conforme são apresentados no Quadro 02, entretanto, apenas duas variáveis apresentaram significância.

Quadro 1 - Variável dos custos ambiental externo avaliado 


\begin{tabular}{|l|c|}
\hline \multicolumn{1}{|c|}{ Custos ambientais externos } & Nível de Significância \\
\hline Pagamento de Multas Ambientais & \\
Município de localização das lavanderias & 0,034 \\
Percentual de reaproveitamento de água & 0,013 \\
\hline
\end{tabular}

Fonte: Dados da pesquisa, 2013.

A primeira variável relacionada com o pagamento das multas foi o município de localização com um nível de significância de $3,4 \%$, onde $79,8 \%$ das lavandeiras de ToritamaPE não pagaram multas ambientais, o que pode indicar que as medidas impostas em 2005 pelo TAC estão sendo cumpridas.

Ao utilizar o teste não paramétrico Exato de Fischer, com as variáveis do custo ambiental externo das multas com o percentual de reaproveitamento de água das lavanderias, obteve-se um nível de significância de 1,3\%, verificando que $100 \%$ das indústrias que reaproveitam o máximo de água de $88 \%$ a $100 \%$ não pagaram multa ambiental;

Seguidas das 78,6\% que não utilizam o reaproveitamento também não pagaram multa, por fim $16,7 \%$ das lavanderias que só reaproveitam de $61 \%$ a $80 \%$ pagaram multas de $\mathrm{R} \$$ $20.000,00$ a $\mathrm{R} \$ 40.000,00$. Portanto, se uma empresa tem estação de tratamento de água menor o índice de exposição a multas e sanções, e as que não têm reaproveitamento de água pagam multa.

Outras relações foram testadas, mas uma que pode ter implicado em várias outras questões, foi que $100 \%$ das lavanderias que não sabem quais documentações são necessárias não conhecem as leis ambientais, apresentando um nível de significando de $0,3 \%$. O que pode ter implicado no descumprimento das leis citadas nesta pesquisa.

A variável referente a Estação de Tratamento de água (ETA) foi testada para responder a hipótese 2, pois como toda lavanderia deverá até 2015 possui uma ETA, servindo de pressuposto para o teste de hipóteses desta pesquisa, portanto foi avaliado se esta variável influência nos custos das lavanderias, conforme mostra o Quadro 03 a seguir:

Quadro 2 - Variável quanto a Estação de Tratamento de Água (ETA)

\begin{tabular}{|l|c|}
\hline \multicolumn{1}{|c|}{ Estação de tratamento de Água } & Nível de Significân \\
\hline Estação de tratamento de água & 0,004 \\
Folha de pagamento dos demais funcionários & 0,014 \\
Gasto com energia elétrica mensal & 0,027 \\
Gasto com produtos para tratamento ambiental & 0,028 \\
Idade do questionado & 0,000 \\
Município de Localização & 0,003 \\
Práticas Sustentáveis Desenvolvidas & 0,011 \\
Tempo na Função & \\
\hline
\end{tabular}

Fonte: Dados da pesquisa, 2013.

O Quadro 3 apresenta as sete relações significantes na pesquisa, nas quais a relação entre estação de tratamento com o valor das folhas de funcionários da empresa resultou que $66,7 \%$ das indústrias que gastam com folha de pagamento de $\mathrm{R} \$ 15.000,01$ a $\mathrm{R} \$ 30.000,00$ investiram de $\mathrm{R} \$ 50.000,01$ a $\mathrm{R} \$ 100.000,00$ na estação de tratamento. Apresentando que as lavanderias que tem investiram mais na ETA tem um maior custo com funcionários.

Ao relacionar-se a estação de tratamento de agua das lavanderias com o gasto de energia verificou-se que há influencia quanto ao custo de energia com a ETA, já que a mesma necessita 
de recursos energéticos para funcionar, porém a maioria das lavanderias questionadas, ou seja, $75 \%$ das indústrias que não sabem informar quanto gastam com energia elétrica investiram até R\$ 50.000 no Tratamento de Água. Este fato implica a dizer que os respondentes precisam se inteirar mais com questões operacionais para controlar os custos.

Os custos de produtos químicos para tratar a água tiveram um nível de relação de 2,7\% quando relacionado com a estação de tratamento, comprovando que $50 \%$ das lavanderias que gastam de $\mathrm{R} \$ 500,01$ a $\mathrm{R} \$ 1.000,00$ com produtos para tratamento da água investiram até $\mathrm{R} \$$ 50.000 na estação de tratamento, comprovando que quando se tem ETA, mais se gasta com produtos.

Outras variáveis também deram significância com a estação de tratamento, entretanto não são relacionadas à hipótese levantada quanto aos custos, entretanto são de extrema relevância como a variável do perfil dos respondentes, que ao se relacionar com o valor de investimento na estação de tratamento de água mostra que quanto mais novos os respondentes, maior a preocupação com o meio ambiente. Demonstrando que $50 \%$ dos mais velhos acima de 51 anos, não têm estação de tratamento e os de 41 a 50 anos investiram até $\mathrm{R} \$ 50.000,00$, tendo com nível de significância 2,76\%.

O que sugeriu outro cruzamento quando ao município de localização das lavanderias quanto ao ativo ambiental, que obteve um grau de significância de $0,01 \%$, no qual se constatou que $50 \%$ das lavanderias de Riacho das Almas não têm estação de tratamento e 70,6\% das localizadas em Caruaru investiram até $\mathrm{R} \$ 50.000,00$ e as estações mais caras estão localizadas na cidade de Toritama, novamente, pode-se perceber que a ação do MPPE está dando resultado nesta Cidade, e assim se espera que aconteça em Caruaru e região.

As praticas ambientais estão relacionadas com a estação de tratamento, até porque ter um ativo para este fim já é uma pratica sustentável, então ao relacionar as duas variáveis, soubese que $100 \%$ das lavanderias que não tem praticas sustentáveis não tem estação de tratamento, o que é obviamente lógico, mas $40 \%$ das que tem reaproveitamento de água gastaram até $\mathrm{R} \$ 50.000$ para fazer ou adquirir a estação de tratamento, o que representou 0,30\% de nível de significância.

A outra variável do perfil dos questionados, que se relacionou com o investimento da estação de tratamento de água, foi o tempo na função de cada um, tendo como grau de significância $1,14 \%$ e expondo que $40 \%$ dos que tem mais tempo na função não tem estação de tratamento,

Ainda nesta analise pode-se observar que $46,7 \%$ dos mais novos na função não sabem informar quanto se gastou para fazer ou adquirir o ativo ambiental, talvez o valor seja desconhecido por ser novo na função e os mais velhos se achem muito experientes, para arcar com as consequências de não ter uma estação de tratamento.

Houve outras correlações relevantes ao estudo, contudo, não era intenção desta pesquisa apresentar variáveis que não fossem relacionadas aos tópicos discutidos acima.

\section{Conclusão}

Este trabalho teve por objetivo verificar se há impacto nos custos operacionais com a implantação de medidas sustentáveis como a instalação uma estação de tratamento de água nas 
lavanderias têxteis do Polo de Confecções do Agreste Pernambucano. Após o teste das hipóteses pode-se verificar alguns fatores importantes na analise

Que 100\% das lavanderias de Riacho das Almas não têm estação de tratamento de água, já o município Toritama têm as estações de tratamento de água com maior custo de construção ou de aquisição.

Outro dado interessante foi que $100 \%$ das lavanderias que reaproveitam o máximo de água não pagaram multa ambiental, até o presente momento, enquanto as que menos reaproveitam água já pagaram multas, ou seja, quanto mais se recicla a água menor o índice de exposição a multas e sanções.

Conclui-se que pelo fato que nem todos os respondentes conhecem seus custos operacionais, nem todas variáveis levantadas no questionário se mostraram significantes, aceitam-se em parte que há influência dos custos ambientais internos ou externos diante a gestão operacional da empresa; bem como a Estação de tratamento de água influência nos custos das lavanderias investigadas.

Apesar desta limitação ressaltar-se que a sustentabilidade não é algo imposto pela mídia ou Governo é uma preocupação de todos, principalmente quem questões econômicas e financeiras, pois através do bom uso dos recursos naturais podem-se evitar multas, reduzir custos e manter a continuidade dos negócios.

\section{Referências}

AZEVEDO, D. B., GIANLUPPI, L. D., \& MALAFAIA, G. C. Os custos ambientais como fator de diferenciação para as empresas. Perspectiva Econômica; v.3, n. 1, p. 82-95, 2007. Disponível em: <http://www.revistas.unisinos.br/index.php/perspectiva_economica/article/view/4357>. Acesso em: 15 nov. 2013, 09:01:37.

BRAGA, CELIA. Contabilidade Ambiental: uma ferramenta para a gestão da sustentabilidade. - 1. Ed. 3 reimpr. - São Paulo: Atlas, 2010.

BRASIL, Resolução CONAMA no 1/1986. Licenciamento Ambiental - Normas e procedimentos. Dispõe sobre critérios básicas e diretrizes gerais para a avaliação de impacto ambiental.

Lei $\mathrm{n}^{\mathbf{0}} \mathbf{9 . 6 0 5}$ de 12/02/1998. Dispõe sobre as sanções penais e administrativas derivadas de condutas e atividades lesivas ao meio ambiente, e dá outras providências. Disponível em: < http://www.planalto.gov.br/ccivil_03/leis/19605.htm>. Acesso em: 27 out. 2013, 09:11:42.

em:

Resolução RDC/ANVISA n⿳ 161/04. Uso do Percloroetileno. Disponível

<http://www.saude.mg.gov.br/index.php?option=com_gmg\&controller=document\&id=509>. Acesso em 28 out. 2013, 10:45:47.

BRITO, GEORGYA ALMEIDA. Sustentabilidade: um desafio para as lavanderias industriais. Revista de Design, inovação e gestão estratégica - REDIGE, SENAI. V. 4, n. 02, ago. 2013. Disponível 
<http://www.cetiqt.senai.br/ead/redige/index.php/redige/article/viewFile/211/251>. Acesso em: 23 ago. 2013, 23:00:09.

CHEN, ZHUO., NGO, HUU HAO., GUO, WENSHAN. A critical review on the evaluation of sustainability of recycled water schemes. Sci Total Environ, v. 426 p. 13-31, 2012. Elsevier BV. Disponível em: < http://www.ncbi.nlm.nih.gov/pubmed/22521163>. Acesso em: 12 out. 2013, 12:37:44.

CiABATTIA, I., CESAROB, F., FARAlliA, L., FATAREllaA, E., TOGNOTTIA, F. Demonstration of a treatment system for purification and reuse of laundry wastewater. Engineering with Membranes. Elsevier B.V. February 2009, p. 451-459. Disponível em: <http://www.sciencedirect.com/science/article/pii/S0011916409003580 >. Acesso em: 12 out. 2013, 12:30:08.

FIJAN, SABINA., FIJAN, REBEKA., TURK, SONJA SOSTAR. Implementing sustainable laundering procedures for textiles in a commercial laundry and thus decreasing wastewater burden. Journal of Cleaner Production, v. 16, p.1258-1263, 2008. Elsevier Ltd. Disponível em: <www.elsevier.com / locate / jclepro >. Acesso em: 12 out. 2013, 12:45:02.

FONSECA, ADRIANA. Empresário abre lavanderia onde não há água. Revista crescer globo. Abril, 2013. Edição 233. Disponível em: <http://revistacrescer.globo.com/Revista/Crescer/0,,EMI83372-15565,00-

EMPRESARIO+ABRE+LAVANDERIA+ONDE+NAO+HA+AGUA.html>. Acesso em 03 jan. 2014, 23:45:08.

MARX, SORAYA. Um pouco da historia e dos tipos de jeans. Blog Mistureba Chic. Disponível em: <http://www.misturebachic.com.br/2013/08/um-pouco-da-historia-e-dostipos-de.html>. Acesso em 02 dez. 2013. 13:45:39.

MELO FILHO, PEDRO PAULO DE. Um estudo de caso quanto à sustentabilidade ambiental promovida por uma lavanderia industrial têxtil de Toritama-PE. Trabalho de conclusão de curso (Graduação em Ciências Contábeis). Faculdade do Vale do Ipojuca - Favip. Caruaru-PE, 2013. Disponível em: $\langle$ repositorio.favip.edu.br $>$... >>. Acesso em 16 nov. 2013, 23:15:48

MINISTÉRIO PÚBLICO DE PERNAMBUCO. Instalação de lavanderias impedidas em Toritama - PE. Disponível em : <http://www.mp.pe.gov.br/index.pl/24082012_lavanderias. Acesso em: 14 nov. 2012, 10:12:39.

PACHER, BRUNO ALESSANDRO; VAZ, CAROLINE RODRIGUES; OLIVEIRA, IVANIR LUIZ DE. Análise do gerenciamento de resíduos de lavanderias de Ponta Grossa. P\&D em Engenharia de Produção, Itajubá, v.9, n.2, p. 121-131, 2011. Disponível em: $<$ http://www.revista-ped.unifei.edu.br/documentos/V09N02/05-0510-V9-N2-

2011.pdf>.Acesso em 15 nov. 2013, 11:08:45.

PERNAMBUCO. (Estado). Instrução Normativa CPRH $\mathbf{N}^{\mathbf{0}}$ 004/2012. Disciplina o enquadramento para Licenciamento Ambiental na CPRH das atividades de Comércio e Serviço, quanto ao Potencial Degradador, conforme previsto no item 6.1 da Tabela 6 do Anexo I, da Lei Estadual $n^{\circ} 14.249$, de 17/12/2010 alterada pela Lei Estadual $n^{\circ} 14.549$, de 21/12/2011. Disponível em: <http://www.cprh.pe.gov.br/ARQUIVOS_ANEXO/IN004;1406;20120829.pdf> Acesso em: 20 mar. 2013, 15:16:08. 
Lei No 14.249, De 17 de Dezembro de 2010. Dispõe sobre licenciamento ambiental, infrações e sanções administrativas ao meio ambiente, e dá outras providências. Disponível em: <http://www.cprh.pe.gov.br/ARQUIVOS_ANEXO/Lei\%20Est\%2014249;141010;20101228. pdf>. Acesso em: 20 mar. 2013, 14:42:57.

PORTO, ANDRÉ ELIAS BRIANESE., SCHOENHAL, MARLISE. Tratamento de efluentes, reúso de água e legislação aplicada em lavanderia têxtil industrial. Revista de Engenharia Ambiental. Espírito Santo do Pinhal , v. 10, n. 2, p. 068-080, mar . /abr . 2013.

REBOUÇAS, ALDO DA CUNHA.; BRAGA, BENEDITO; TUNDISI, JOSÉ GALIZIA. (organizadores). Águas Doce no Brasil: capital ecológico uso e conservação. 3. Ed. São Paulo: Escrituras, 2006.

RESENDE, LETÍCIA PASSOS. Reuso na indústria têxtil e lavanderias. Revista Hydro. São Paulo, 2012. Disponível em: <http://sindlav.com.br/wp-content/uploads/2012/05/H66Especial.pdf.> Acesso em: 02 jun. 2013, 17:23:08.

RIBEIRO, MAÍSA DE SOUZA. Contabilidade Ambiental. São Paulo: Saraiva, 2006.

SEBRAE. Crescimento das lavanderias. 2012.Agência do Estado - SEBRAE-PE. Disponivel em:

$<\mathrm{http}: / / \mathrm{www}$. sebraesc.com.br/novos_destaques/oportunidade/default.asp?materia=20072> Acesso em: 25 jan. 2013, 07:35:18.

Disponível Lavanderias do Agreste ganham Selo Verde. SEBRAE-PE, 2013. <http://www pe.agenciasebrae.com br/noticia $\mathrm{kmf}$ ?canal=107\&cod=12721380>. Acesso em: 11 out. 2012, 08:24:35.

SIEGEL, SIDNEY. Estatística não paramétrica para ciências do comportamento. São Paulo: McGraw-Hill, 1975.

SILVA FILHO, ANTONIO ROMÃO ALVES DA. Desenvolvimento de Sistema Simplificado de Gestão ambiental Aplicado a Micro e Pequenas Empresas de Beneficiamento de Jeans. Recife-PE, 2013. Tese de Doutorado (Doutorado em Engenharia Civil). Universidade Federal De Pernambuco - UFPE.

SINDILAV. Sustentabilidade em lavanderias de jeans. Sindilav Notícias: Set/Out - 2011 $\mathrm{n}^{\circ}$ 164. Disponível em: <http://sindilav.com.br/noticias/set-out-2011/sustentabilidade-emlavanderias-de-jeans/>. Acesso em: 25 set. 2013, 20:55:15

TEIXEIRA, SÉRGIO. Os perigos dos metais pesados. 2010. Disponível em: $<$ http://www.velhosamigos.com.br/autores/teixeira/teixeira5.html>. Acesso em 28 out. 2013, 10:50:19.

THOREN, RYAN I., ATWATER, JIM., BERUBE, PIERRE. A model for analyzing water reuse and resource recovery potential in urban areas. Canadian Journal of Civil Engineering. v. 39.n.1, p. 1202, 2012. NRC Research Press. Disponível em: <http://www.nrccnrc.gc.ca/main_e.html>. Acesso em: 12 out. 2013, 12:57:46. 
TINOCO, JOÃO EDUARDO PRUDÊNCIO. KRAEMER, MARIA ELISABETH PEREIRA. Contabilidade e gestão ambiental. - $3^{\circ}$ ed. São Paulo: Atlas, 2011.

VIÑOLAS I MARLET, JOAQUIM. Diseño ecológico: hacia un diseño y uma producción en armonía con la naturaleza. 1. Ed. Barcelona - ESP: Art. Blume, 2005. 